\title{
EFEITO DE AUXINAS E CONDIÇÕES DE CULTIVO NO ENRAIZAMENTO IN VITRO DE PORTA-ENXERTOS DE MACIEIRA 'M-9'
}

\author{
ELIZETE BEATRIZ RADMANN², JOSÉ CARLOS FACHINELLO ${ }^{3}$, JOSÉ ANTONIO PETERS ${ }^{4}$
}

\begin{abstract}
RESUMO: A utilização de mudas com características desejáveis, tanto genéticas quanto sanitárias, é um fator importante para o sucesso na produção de mudas. A micropropagação, em comparação às formas tradicionais de propagação vegetativa, possibilita aumentar a produção e a qualidade das mudas. Nesta técnica, a rizogênese é uma etapa crucial para o desenvolvimento das plantas propagadas in vitro. Neste contexto, objetivou-se testar condições de cultivo, tipos e concentrações de auxinas para o enraizamento in vitro do porta-enxerto de macieira M-9. Como explantes, foram utilizadas brotações $(1 \mathrm{~cm})$, as quais foram cultivadas em meio MS/2. As auxinas utilizadas foram AIA, ANA e AIB, nas concentrações de 0,$0 ; 0,5 ; 1,0$; 5,$0 ; 10 ; 20 ; 50$ e $100 \mu \mathrm{M}$. Foram testadas duas condições de incubação: na primeira, os frascos foram mantidos sob luz ( 30 dias) e, na segunda, os frascos foram mantidos por cinco dias no escuro com posterior transferência para luz ( 25 dias). Em ambas as condições, os explantes foram expostos a tratamentos com auxina, durante todo o tempo ou apenas por dez dias, com posterior transferência para meio sem auxina. As variáveis analisadas foram: porcentagem de enraizamento, número e comprimento de raiz, tipo de raiz e porcentagem de sobrevivência de plantas na fase de aclimatização. O AIA induziu maior porcentagem de enraizamento, plantas com melhor sistema radicular e parte aérea nas concentrações mais altas; porém, quando foi utilizado AIB e ANA, essas características foram observadas nas concentrações mais baixas. Os tratamentos em que os explantes foram cultivados por apenas dez dias, em meios com auxinas, apresentaram, em geral, melhores respostas. Observou-se maior porcentagem de plantas aclimatizadas nos tratamentos com AIA.
\end{abstract}

Termos para indexação: macieira, micropropagação, cultivo in vitro, escuro.

\section{EFFECT OF AUXIN AND CULTIVATION CONDITIONS IN IN VITRO ROOTING OF ROOT-STOOCK OF APPLE 'M-9'}

\begin{abstract}
The utilization of trees with desirable characteristics, genetics and sanitary, is an important factor for the success in plant propagation. The micropropagation, in comparison with the traditional vegetative propagation methods, helps to increase the production and to get trees with higher sanitary quality. In this technique rooting is a crucial stage to the development of the plants propagated in vitro. In such context, it was aimed to test cultivation conditions and types and concentrations of auxin for the rooting in vitro of the cv. M-9 apple tree root-stook. Shoots (1cm) were used, and they were cultivated in half MS. medium, with the addition of gelrite for their solidification. The auxins used were IAA, NAA and IBA, in 0.5; $1.0 ; 5.0 ; 10.0 ; 20.0 ; 50.0$ and $100.0 \mu \mathrm{M}$ concentrations. Two different incubation conditions were tested. In the first one, the explants were kept into the light (30 days), and in the second one, the explants were kept for 5 days in the dark with further transfer to light (25 days). In both conditions, the explants were exposed to plant growth regulators during all the time, or just for ten days, with further transfer to a medium without plant growth regulator. The variables analysed were as follows: rooting percentage; number, length and kind of root, while in the shoot test, apart from these, the survival percentage in the stage of aclimatization was evaluated. IAA induced higher rooting percentage, plants with better root system and leaves in the highest concentrations, but when it was used IBA and NAA these characteristics were observed in the lowest concentrations. When the explants were cultivated for just ten days in medium added writh auxins, they presented, in general, better results.
\end{abstract}

Index terms: apple tree, micropropagation, in vitro culture, darkness.

\section{INTRODUÇÃO}

A cultura da macieira possui papel de destaque no cenário frutícola brasileiro. Atualmente, a área cultivada no Brasil está estimada em 30 mil hectares, com uma produção aproximada de 967 mil toneladas. Na região Sul do Brasil, concentra-se a maior produção de maçã, onde o Estado de Santa Catarina lidera a produção com 500 mil ton na safra 99/00, e em segundo lugar, com 427 mil ton, o Estado do Rio Grande do Sul (ABPM, 2002).

Para atender às demandas de mudas da pomicultura nacional por material vegetativo, é requerida grande quantidade de material propagativo. Já que as técnicas convencionais de propagação não possibilitam alcançar tal objetivo a curto prazo, a micropropagação permite acelerar os métodos convencionais de propagação vegetativa (Grattapaglia \& Machado, 1998).

A formação de raízes adventícias nas partes aéreas obtidas, no estádio de multiplicação, permite a constituição de plantas completas, para posterior transferência a condições ex vitro. Muitas vezes, as raízes formadas não apresentam características adequadas às funções de absorção, determinando, dentre outros fatores, a morte das mudas, quando transferidas para o solo. O processo de enraizamento é muito complexo, incluindo fatores fisiológicos, bioquímicos e biológicos (fatores internos) que interagem com os fatores externos. Além disso, a complexidade é aumentada pela variabilidade genética devido à multiplicidade das espécies e cultivares (Assis \& Teixeira, 1998).

O controle do desenvolvimento de raízes adventícias é influenciado por substâncias reguladoras de crescimento. As auxinas são os únicos reguladores de crescimento que aumentam a formação de primórdios radiculares (Taiz \& Zeiger, 1991).

Embora existam espécies que formam raízes adventícias apenas com os níveis endógenos de auxina, geralmente é necessário adicionar auxina exógena para estimular a rizogênese (Grattapaglia \& Caldas, 1990). Tipos e concentrações de auxinas são as variáveis que mais influenciam no enraizamento, e a adição de outros biorreguladores é desnecessária ou até prejudicial (Grattapaglia \& Machado, 1998). Lee \& Ko (1984) observaram efeito inibitório com a utilização de ácido giberélico na indução das raízes em macieira.

O ácido 3-indolacético (AIA) é a principal auxina das plantas, sendo ativa em concentrações extremamente baixas. O AIA não é apenas sintetizado nas plantas, mas também inativado durante os processos de crescimento e diferenciação. A oxidação do AIA pode ocorrer por um processo de foto-oxidação e através de reações de oxidação catalisadas por enzimas (AIA-oxidase). Além dos processos de oxidação, o AIA pode ligar-se a outras moléculas na planta, produzindo conjugados que podem reter ou perder a atividade auxínica (Salisbury, 1991).

Nos meios de cultura para o enraizamento, tipos e concentrações de

\footnotetext{
1 (Trabalho 133/2001). Recebido: 16/08/2001. Aceito para publicação: 21/08/2002.

Parte da dissertação de Mestrado do primeiro autor, Mestrado em Fruticultura de Clima Temperado FAEM/UFPel, pesquisa financiada pela CAPES.

2Eng. Agr. MSc. Fruticultura de Clima Temperado (FAEM/UFPel) eradmann@ hotmail.com

3 Eng. Agr. Dr., Prof. Titular do Dept. de Fitotecnia (FAEM/UFPel) jfachi@ufpel.tche.br

4Eng. Agr. Dr., pesquisador CEPEC/CEPLAC - Itabuna/Ba - peters@ @epec.br
} 
auxinas são as variáveis que, em geral, mais influenciam.

Quando a concentração de auxina no meio é excessiva, ocorre formação de calo na base do explante, comprometendo a rizogênese e o crescimento da parte aérea. Uma toxidez de auxina durante o enraizamento pode manifestar-se apenas na fase de alongamento das raízes. Por esta razão é, às vezes, recomendada a utilização de dois meios de cultura para a rizogênese. Primeiramente, as partes aéreas permanecem em meio com auxina, favorecendo a indução e posteriormente passaria para meio sem auxina, estimulando assim a rizogênese e o crescimento das raízes. Este processo tem sido adotado com freqüência em espécies lenhosas, coníferas e frutíferas (Fett Neto et al., 1992).

As auxinas podem ser utilizadas isoladamente ou em combinação, no meio de enraizamento, sendo que o AIA, ácido indolilbutírico (AIB) e ácido $\alpha$-naftalenoacético (ANA) são as auxinas mais empregadas, em concentrações que variam conforme a espécie e/ou cultivar. As concentrações mais freqüentes estão na faixa de 0,5 a 5,0 $\mu \mathrm{M}$ (Gattapaglia \& Machado, 1998)

Vesco \& Guerra (1999), trabalhando com goiabeira serrana, testaram brotações em meio de enraizamento contendo $1 / 4$ e 1/2 de MS, com adição de AIB $(0,5 ; 1,2 ; 5,0$ e $15,0 \mu \mathrm{M})$ e ANA $(2,7 \mu \mathrm{M})$ e carvão ativado. Os melhores resultados foram obtidos em meio basal com 1/4 de MS adicionado de 1,2 $\mu \mathrm{M}$ de AIB e carvão ativado. Ferri \& Fortes (1993) submeteram brotações de kiwi cv. Matua a tratamentos com reguladores AIB, ANA e AIA nas concentrações de 0,0; 0,5; 1,5 e 4,5 $\mu \mathrm{M}$ adicionados ao meio básico MS. Os autores verificaram que o AIB foi mais eficaz nas concentrações de 2,8 a 3,8 $\mu \mathrm{M}$ para porcentagem de enraizamento, número e comprimento de raízes primárias e secundárias. Já o ANA apresentou concentrações ideais entre 2,5 e 3,5 $\mu \mathrm{M}$ para porcentagem de enraizamento e número de raízes secundárias, enquanto o AIA, nas concentrações de 2,4 a 3,0 $\mu \mathrm{M}$, aumentou o número de raízes e o comprimento destas. Borges et al. (1997), utilizando $5 \mathrm{mg} / \mathrm{l} \mathrm{de} \mathrm{AIB,}$ obtiveram de 60 a $70 \%$ de sobrevivência de plantas de banana quando transferidas para o solo. De acordo com Pasqual et al. (1991), mudas de amora-preta desenvolveram bem e apresentaram bom enraizamento oriundas de meio MS acrescido de AIB ou ANA, na concentração de 0,1 $\mathrm{mg} / \mathrm{l}$.

Nunes et al. (1999), trabalhando com o porta-enxerto de macieira Marubakaido, verificaram que $0,49 \mu \mathrm{M}$ de AIB resultaram nos melhores índices de enraizamento, proporcionando $100 \%$ dos explantes enraizados no vigésimo quinto dia de cultivo. Já com relação à cultivar Fred Hough, o AIB e o ANA mostraram respostas similares na percentagem de enraizamento, sendo 3,0 $\mu \mathrm{M}$ a melhor concentração, com $90 \%$ de explantes enraizados. Explantes tratados com AIA apresentaram resposta crescente de acordo com a concentração, mas só atingiram $66 \%$ de enraizamento com 5,0 $\mu \mathrm{M}$ (Centellas et al., 1999). O porta-enxerto Marubakaido apresentou melhor porcentagem de enraizamento quando foi utilizado 3,0 $\mu \mathrm{M}$ de AIB (Zanol, 1996).

Outro fator que pode influenciar na indução das raízes é a luminosidade, pois a presença da luz pode ocasionar a redução dos teores endógenos de AIA, assim como o acúmulo de fenóis e seus subprodutos que inibem o enraizamento (Assis \& Teixeira, 1998).

O porta-enxerto M-9 é o mais utilizado no Brasil e no mundo, tendo como característica principal controlar o vigor da planta, ou seja, tem efeito ananizante sobre a copa. Além de reduzir o porte da planta, o M-9 induz mais rapidamente a frutificação e é um dos únicos portaenxertos que apresenta boa resistência à podridão do colo (Phytophthora cactorum) (Barrit, 1999).

Em vista disso, objetivou-se, com o presente trabalho, verificar o efeito de diferentes tipos e concentrações de auxinas, e avaliar o efeito do escuro no enraizamento in vitro do porta-enxerto M-9.

\section{MATERIALEMÉTODOS}

O trabalho foi conduzido no Laboratório de Cultura de Tecidos de Plantas do Instituto de Biologia da Universidade Federal de Pelotas, Rio Grande do Sul.
Em condições assépticas, foram repicados segmentos de brotações terminais com $1 \mathrm{~cm}$ de comprimento do porta-enxerto M-9, que foram cultivadas em meio MS (Murashige \& Skoog, 1962) (Tabela 1) com os sais reduzidos à metade, acrescidos de mio-inositol (100mg.L $\left.\mathrm{L}^{-1}\right)$ e sacarose (30g. $\left.\mathrm{L}^{-1}\right)$, e pH ajustado para 5,8. Para sua solidificação, foi usado gelrite $\left(2 \mathrm{~g} \cdot \mathrm{L}^{-1}\right)$. Foram utilizados três tipos de auxina: AIA, AIB e ANA, em sete concentrações e tratamento-controle $(0,5 ; 1,0 ; 5,0 ; 10 ; 20$; 50 e $100 \mu \mathrm{M})$. Os meios contendo os explantes foram testados sob duas condições de incubação: na primeira, os frascos foram mantidos na luz (30 dias) e, na segunda, os frascos foram mantidos por cinco dias no escuro com posterior transferência para luz (25 dias). Em ambas as condições, os explantes foram expostos aos reguladores vegetais, durante todo o tempo (luz+auxina e escuro+auxina) ou apenas por dez dias, com posterior transferência para meio sem auxina (luz-auxina e escuro-auxina). Após os trinta dias no meio de enraizamento, as plantas foram trans-

TABELA 1 - Composição do meio de cultura MS (Murashige \& Skoog, 1962)

\begin{tabular}{|c|c|c|c|c|}
\hline $\begin{array}{l}\text { Solução } \\
\text { estoque }\end{array}$ & Nutrientes & $\begin{array}{c}\text { Concentração } \\
\text { solução estoque }\end{array}$ & $\begin{array}{c}\text { Concentração } \\
\text { final }\end{array}$ & $\begin{array}{c}\text { Concentração no } \\
\text { meio de cultura }\end{array}$ \\
\hline A & $\mathrm{NH}_{4} \mathrm{NO}_{3}$ & $82,5 \mathrm{~g} \cdot \mathrm{L}^{-1}$ & $1,650 \mathrm{~g} \cdot \mathrm{L}^{-1}$ & $20 \mathrm{ml} \cdot \mathrm{L}^{-1}$ \\
\hline B & $\mathrm{KNO}_{3}$ & $95,0 \mathrm{~g} \cdot \mathrm{L}^{-1}$ & $1,900 \mathrm{~g} \cdot \mathrm{L}^{-1}$ & $20 \mathrm{ml} \cdot \mathrm{L}^{-1}$ \\
\hline \multirow[t]{4}{*}{ C } & $\mathrm{MgSO}_{4} .7 \mathrm{H}_{2} \mathrm{O}$ & $74,0 \mathrm{~g} \cdot \mathrm{L}^{-1}$ & $0,370 \mathrm{~g} \cdot \mathrm{L}^{-1}$ & $5,0 \mathrm{ml} \cdot \mathrm{L}^{-1}$ \\
\hline & $\mathrm{MnSO}_{4} \cdot \mathrm{H}_{2} \mathrm{O}$ & $3,38 \mathrm{~g} \cdot \mathrm{L}^{-1}$ & $0,0017 \mathrm{~g} \cdot \mathrm{L}^{-1}$ & \\
\hline & $\mathrm{ZnSO}_{4} .7 \mathrm{H}_{2} \mathrm{O}$ & $1,72 \mathrm{~g} \cdot \mathrm{L}^{-1}$ & $0,0086 \mathrm{~g} \cdot \mathrm{L}^{-1}$ & \\
\hline & $\mathrm{CuSO}_{4} \cdot 5 \mathrm{H}_{2} \mathrm{O}$ & $5,00 \mathrm{~g} \cdot \mathrm{L}^{-1}$ & $0,025 \mathrm{mg} \cdot \mathrm{L}^{-1}$ & \\
\hline D & $\mathrm{CaCl}_{2} .2 \mathrm{H}_{2} \mathrm{O}$ & $88,0 \mathrm{~g} \cdot \mathrm{L}^{-1}$ & $440,0 \mathrm{mg} \cdot \mathrm{L}^{-1}$ & $5,0 \mathrm{ml} \cdot \mathrm{L}^{-1}$ \\
\hline \multirow[t]{5}{*}{ E } & $\mathrm{H}_{3} \mathrm{BO}_{3}$ & $1,24 \mathrm{~g} \cdot \mathrm{L}^{-1}$ & $6,200 \mathrm{mg} \cdot \mathrm{L}^{-1}$ & $5,0 \mathrm{ml} \cdot \mathrm{L}^{-1}$ \\
\hline & \multirow{2}{*}{$\begin{array}{r}\mathrm{KH}_{2} \mathrm{PO}_{4} \\
\mathrm{Kl}\end{array}$} & $34,0 \mathrm{~g} \cdot \mathrm{L}^{-1}$ & $170,0 \mathrm{mg} \cdot \mathrm{L}^{-1}$ & \\
\hline & & $0,16 \mathrm{~g} \cdot \mathrm{L}^{-1}$ & $0,830 \mathrm{mg} \cdot \mathrm{L}^{-1}$ & \\
\hline & \multirow{2}{*}{$\begin{array}{l}\mathrm{Na}_{2} \mathrm{MoO}_{4} \cdot 2 \mathrm{H}_{2} \mathrm{O} \\
\mathrm{CaCl}_{2} \cdot 6 \mathrm{H}_{2} \mathrm{O}\end{array}$} & $0,05 \mathrm{~g} \cdot \mathrm{L}^{-1}$ & $0,250 \mathrm{mg} \cdot \mathrm{L}^{-1}$ & \\
\hline & & $0,005 g \cdot L^{-1}$ & $0,025 \mathrm{mg} \cdot \mathrm{L}^{-1}$ & \\
\hline \multirow[t]{2}{*}{$\mathrm{F}$} & $\mathrm{Na}_{2}$ EDTA & $7,450 \mathrm{~g} \cdot \mathrm{L}^{-1}$ & $37,25 \mathrm{mg} \cdot \mathrm{L}^{-1}$ & $5,0 \mathrm{ml} \cdot \mathrm{L}^{-1}$ \\
\hline & $\mathrm{FeSO}_{4} \cdot 7 \mathrm{H}_{2} \mathrm{O}$ & $5,570 \mathrm{~g} \cdot \mathrm{L}^{-1}$ & $27,85 \mathrm{mg} \cdot \mathrm{L}^{-1}$ & \\
\hline \multirow[t]{4}{*}{ G } & Tiamina & $0,050 \mathrm{~g} \cdot \mathrm{L}^{-1}$ & $0,500 \mathrm{mg} \cdot \mathrm{L}^{-1}$ & $5,0 \mathrm{ml} \cdot \mathrm{L}^{-1}$ \\
\hline & Piridoxina & $0,050 \mathrm{~g} \cdot \mathrm{L}^{-1}$ & $0,500 \mathrm{mg} \cdot \mathrm{L}^{-1}$ & \\
\hline & Àcido nicotínico & $0,050 \mathrm{~g} \cdot \mathrm{L}^{-1}$ & $0,500 \mathrm{mg} \cdot \mathrm{L}^{-1}$ & \\
\hline & Glicina & $0,200 \mathrm{~g} \cdot \mathrm{L}^{-1}$ & $2,000 \mathrm{mg} \cdot \mathrm{L}^{-1}$ & \\
\hline
\end{tabular}

plantadas e aclimatizadas em bandejas de isopor com substrato Plantmax. As variáveis mensuradas compreenderam: porcentagem de explantes enraizados, número de raiz por explante, comprimento e tipo de raiz, e porcentagem de sobrevivência de plantas na fase de aclimatização.

O delineamento experimental utilizado foi o de blocos ao acaso, em esquema fatorial com quatro repetições, sendo que cada repetição continha 5 explantes, totalizando 20 explantes por tratamento. As variáveis porcentagem de enraizamento e de sobrevivência foram transformadas segundo arco-seno raiz quadrada de $\mathrm{x} / 100$ e o número de raízes por explante segundo raiz quadrada de $(x+0,5)$. Os resultados foram submetidos à análise de variância, sendo utilizado regressão polinomial para o fator concentração, e comparação de médias pelo Teste de Duncan, ao nível de significância de 5\% para os fatores auxina e cultivo.

\section{RESULTADOS E DISCUSSÃO}

A não-utilização da análise de regressão para o fator concentração, deve-se ao fato de nenhum dos modelos de equações lineares adequarem-se aos dados, demonstrados pelos baixos coeficientes de determinação $\left(\mathrm{R}^{2}\right)$. Sendo assim, optou-se pela comparação múltipla de médias.

Os resultados obtidos durante a fase de enraizamento in vitro 
evidenciam a importância das auxinas para o enraizamento de explantes de macieira, cultivar M-9 (Tabela 2). Pois, nos tratamentos- controle, embora tenha ocorrido a formação de raízes, a porcentagem foi baixa. Estes resultados estão de acordo com trabalhos encontrados na literatura, que apontam a necessidade da inclusão de uma auxina nos meios de enraizamento de espécies frutíferas, como ameixeira cv. Santa Rosa (Magalhães \& Peters, 1991), pereira cv. Carrick (Leite et al., 1994) e macieira cv. Fred Hough (Centellas et al., 1999).

O AIA induziu maior porcentagem de enraizamento nas concentrações mais altas $(20,50$ e $100 \mu \mathrm{M})$ no cultivo escuro+auxina (Tabela 2). Isto demonstra que esta auxina apresenta efeito menos acentuado que as outras auxinas testadas, pois induziu o enraizamento numa ampla faixa de concentração $(0,5$ a $100 \mu \mathrm{M})$. Estes efeitos também foram verificados por Centellas et al. (1999), quando trabalharam com macieira cv. Fred Hough, ou seja, obtiveram respostas crescentes de acordo com a concentração de AIA no meio de cultura. Em contrapartida, com relação ao AIB e ANA, as maiores respostas ocorreram nas concentrações mais baixas, ocorrendo uma redução na porcentagem de enraizamento com aumento da concentração (Tabela 2). Estes efeitos diferenciais podem ser explicados em função das próprias características de cada auxina. O AIA é fotooxidado muito rapidamente no meio de cultura (50\% em 24 horas), o AIB levemente (10\%), sendo o ANA muito mais estável que o AIA e o AIB (Nissen \& Sutter, 1990). O AIA ainda é, também, fortemente oxidado, principalmente através da AIA-oxidase (Van Der Krieken et al., 1993). Assim, o melhor efeito com AIA nas concentrações mais altas pode estar relacionado à eliminação desta auxina, quando as culturas são transferidas do escuro para a luz. De Klerk et al. (1997), trabalhando com macieira cv. Jork 9, salientam que cada tipo de auxina tem velocidade diferente de absorção, o que determina, muitas vezes, concentrações variáveis destas substâncias no interior das células, para uma mesma concentração no meio de cultura. Por outro lado, no cultivo luz+auxina, não houve diferença significativa entre as concentrações utilizadas, mas o AIA e o ANA foram superiores ao AIB nas concentrações mais altas $(50$ e $100 \mu \mathrm{M})$ (Tabela 2).

O efeito tóxico do ANA e AIB observado na indução do enraizamento, nas altas concentrações utilizadas, determinou a formação de calo na base dos explantes e diminuição do desenvolvimento da parte aérea, principalmente nas concentrações de 50 e $100 \mu \mathrm{M}$ e no sistema em que os explantes foram submetidos a um período de escuro. Estes resultados podem ser explicados com base na ação da luz na degradação destas auxinas (Nissen \& Sutter, 1990), bem como do efeito mais localizado destas substâncias em relação ao AIA (Taiz \& Zeiger, 1991). Outra possível explicação seria o metabolismo diferencial destas auxinas nas células vegetais. Assim, o ANA seria apenas conjugado, o AIA conjugado e oxidado, e o AIB conjugado e metabolizado (Smulders et al., 1990).

Quando comparamos os tipos de cultivos, podemos observar que a maioria das respostas obtidas nos tratamentos luz-auxina e escuroauxina, aumentaram ou não diferiram significativamente daquelas obtidas em meios com a presença constante das auxinas (Tabela 2). Segundo De Klerk et al. (1997), a indução das raízes adventícias ocorre nos primeiros cinco dias após a transferência para o meio de enraizamento, ou seja, inferior ao utilizado neste trabalho (dez dias). Assim, após este período, a presença de auxinas, no meio, afetaria somente o crescimento das raízes já formadas, para o qual é necessário concentrações mais baixas (Salisbury \& Roos, 1991).

Em relação ao número de raízes por explante, verificaram-se respostas diferentes em relação à concentração empregada. O AIA induziu maior número de raízes em altas concentrações, enquanto AIB e ANA em baixas, nos cultivos com auxina constante no meio (Tabela 3 ). Pois o AIA, por ser considerada uma auxina instável, degradando-se facilmente pela ação da luz e/ou pela AIA-oxidase, é considerada fraca comparada ao ANA e AIB (Caldas et al., 1990). Isso explica, em parte, as melhores respostas nas concentrações mais altas. Em contrapartida, quando as brotações foram mantidas por dez dias em meio com auxina, $\mathrm{o}$ AIB apresentou respostas semelhantes entre as concentrações no cultivo escuro-auxina, e induziu maior número de raízes na concentração mais alta utilizada, no cultivo luz-auxina (Tabela 3 ). Estes efeitos diferenciais podem ser devidos, à presença não constante da auxina no meio de cultura, como também pela presença da luz, principalmente no cultivo luz-auxina. Pode-se observar que o número de raízes por explante, obtido nos cultivos em que estes foram mantidos em meio com auxina por dez dias, aumentou ou não diferiu significativamente daqueles obtidos em meios com a presença constante das auxinas, na maioria das concentrações utilizadas (Tabela 3). O que pode explicar este fato, é a toxidez causada pelas auxinas ao tecido. Estes resultados estão de acordo com Zanol et al. (1998), que constataram que a transferência de brotações de Marubakaido para meio sem auxina resultou em menor formação de calo, melhorou a qualidade das raízes, levando a um melhor desenvolvimento das plantas. Desta forma, revertem-se os problemas causados pelas altas concentrações de auxinas por período prolongado. No entanto, aumenta o trabalho no laboratório, aumentando também os custos (Maene \& Debergh, 1987).

TABELA 2 - Porcentagem de explantes enraizados do porta-enxerto M9 - FAEM/UFPel, 2001

\begin{tabular}{|c|c|c|c|c|c|c|c|c|c|}
\hline \multirow{2}{*}{$\begin{array}{l}\text { TIPOS DE } \\
\text { CULTIVO }\end{array}$} & \multirow[b]{2}{*}{ AUXINAS } & \multicolumn{8}{|c|}{ CONCENTRAÇÕES ( M) } \\
\hline & & 0,0 & 0,5 & 1,0 & 5,0 & 10 & 20 & 50 & 100 \\
\hline & AIA & $8,00 a^{1} E$ & $50,00 \mathrm{~b} C D$ & $39,51 \mathrm{CD}$ & $\overline{55,51 \mathrm{~b} C D}$ & 80,00 a BC & $88,38 \mathrm{a} A \mathrm{BB}$ & $98,66 \mathrm{aAB}$ & $100,0 \mathrm{aA}$ \\
\hline \multirow{2}{*}{$\begin{array}{c}\text { ESCURO + } \\
\text { AUXINA }\end{array}$} & ANA & $8,01 \mathrm{aC}$ & $95,17 \mathrm{a} A B$ & $100,0 \mathrm{aA}$ & 88,38 a $A B$ & 91,98 a $A B$ & $80,42 \mathrm{aB}$ & $0,00 \mathrm{bC}$ & $0,00 \mathrm{bC}$ \\
\hline & AIB & $7,91 \mathrm{a} C D$ & $50,00 \mathrm{~b} A \mathrm{~B}$ & $75,40 \mathrm{bA}$ & $39,51 \mathrm{~b} A B$ & $39,51 \mathrm{~b} \mathrm{AB}$ & $24,59 \mathrm{~b} \mathrm{BC}$ & $0,00 \mathrm{bD}$ & $0,00 \mathrm{bD}$ \\
\hline \multirow{3}{*}{$\begin{array}{c}\text { LUZ + } \\
\text { AUXINA }\end{array}$} & & 30,00 a B & $55,51 \mathrm{aAB}$ & $55,51 \mathrm{a} A B$ & $61,48 \mathrm{aAB}$ & $55,02 \mathrm{aAB}$ & 75,40 a A & 80,00 a A & 4,61 \\
\hline & ANA & $29,50 \mathrm{aA}$ & 34,18 a A & 44,97 a A & $44,97 \mathrm{aA}$ & 44,97 a & 44,48 a A & $49,50 \mathrm{ab} A$ & 44,97 a A \\
\hline & AIB & $29,50 \mathrm{aA}$ & 55,51 a $A$ & 60,48 a $A$ & 50,00 a A & 50,00 a A & 50,00 a A & $44,48 \mathrm{bA}$ & $29,50 \mathrm{bA}$ \\
\hline \multirow{3}{*}{$\begin{array}{l}\text { ESCURO - } \\
\text { AUXINA }\end{array}$} & A & $7,80 \mathrm{aB}$ & $94,72 \mathrm{aA}$ & $94,72 \mathrm{aA}$ & $94,72 \mathrm{aA}$ & 88,38 a & $94,72 \mathrm{aA}$ & 94,72 a $A$ & $71,87 \mathrm{a}$ \\
\hline & ANA & $8,01 \mathrm{aB}$ & 84,61 a A & 94,72 a A & 76,28 a A & 76,38 a A & 70,49 a A & 80,42 a $A$ & 76,28 a A \\
\hline & AIB & $8,01 \mathrm{a} B$ & 91,98 a $A$ & 92,53 a A & 99,35 a A & 99,35 a A & 94,72 a A & 94,72 a A & 88,38 a $A$ \\
\hline \multirow{3}{*}{$\begin{array}{l}\text { LUZ. } \\
\text { AUXINA }\end{array}$} & AlA & $19,57 \mathrm{aB}$ & $91,98 \mathrm{aA}$ & 98,66 a A & 98,66 a A & 98,66 aA & $98,66 \mathrm{aA}$ & 98,66 a $A$ & 98,66 a \\
\hline & ANA & 19,57 a C & $44,97 \mathrm{~b} \mathrm{BC}$ & $80,81 \mathrm{ab} A \mathrm{~B}$ & 391,98 a A & 91,98 a $A$ & $65,34 \mathrm{bAB}$ & $65,81 \mathrm{bAB}$ & 66,78 b AB \\
\hline & AIB & $19,00 \mathrm{a} \mathrm{C}$ & $71,43 a b B$ & 65,81 b B & $88,38 a A B$ & 98,66 a A & 98,66 a A & 98,66 a A & 98,66 a A \\
\hline
\end{tabular}

${ }^{1}$ Médias seguidas por mesma letra minúscula na coluna não diferem entre si para o fator fonte de auxinas, dentro dos fatores tipo de cultivo e concentração, e médias seguidas por mesma letra maiúscula na linha não diferem entre si para o fator concentração, dentro dos fatores fonte de auxina e tipo de cultivo (Coeficiente de variação: 25,74$)$.

TABELA 3 - Número de raízes por explante enraizado do porta-enxerto M-9 - FAEM/UFPel, 2001

\begin{tabular}{|c|c|c|c|c|c|c|c|c|c|}
\hline \multirow{2}{*}{$\begin{array}{l}\text { TIPOS DE } \\
\text { CULTIVO }\end{array}$} & \multirow[b]{2}{*}{ AUXINAS } & \multicolumn{8}{|c|}{ CONCENTRAÇÕES ( M) } \\
\hline & & 0,0 & 0,5 & 1,0 & 5,0 & 10 & 20 & 50 & 100 \\
\hline & AIA & $0,70 a^{1} E$ & $2,61 \mathrm{~b} \mathrm{D}$ & $3,61 \mathrm{bD}$ & $8,49 a \mathrm{~B}$ & 9,36 a B & $12,71 \mathrm{aA}$ & $8,15 \mathrm{aB}$ & $5,52 \mathrm{aC}$ \\
\hline \multirow{3}{*}{$\begin{array}{c}\text { ESCURO + } \\
\text { AUXINA }\end{array}$} & ANA & $0,61 \mathrm{aD}$ & 4,61 a BC & $6,51 \mathrm{aA}$ & $4,43 \mathrm{~b} \mathrm{BC}$ & $3,43 \mathrm{bC}$ & $3,86 \mathrm{~b} \mathrm{BC}$ & $0,00 \mathrm{bD}$ & $0,00 \mathrm{bD}$ \\
\hline & AIB & $0,61 \mathrm{a} \mathrm{C}$ & $4,59 \mathrm{aA}$ & $4,21 \mathrm{bA}$ & $3,68 \mathrm{bA}$ & $2,20 \mathrm{CB}$ & $1,46 \mathrm{cB}$ & $0,00 \mathrm{bC}$ & $0,00 \mathrm{bC}$ \\
\hline & Ï̈̈ & $2,65 \mathrm{aC}$ & $4,49 \mathrm{aB}$ & $4,32 \mathrm{~b} \mathrm{~B}$ & $4,37 \mathrm{bB}$ & $11,11 \mathrm{aA}$ & $12,02 \mathrm{aA}$ & $11,55 \mathrm{aA}$ & $10,97 \mathrm{aA}$ \\
\hline \multirow{3}{*}{$\begin{array}{c}\text { LUZ + } \\
\text { AUXINA }\end{array}$} & ANA & $2,73 \mathrm{aA}$ & $3,00 \mathrm{~b} \mathrm{~A}$ & $2,73 \mathrm{cA}$ & $3,01 \mathrm{bA}$ & $2,85 \mathrm{cA}$ & $2,66 \mathrm{bA}$ & $2,25 \mathrm{bA}$ & $1,94 \mathrm{bA}$ \\
\hline & AIB & $2,73 \mathrm{aC}$ & 4,85 a B & $6,97 \mathrm{aA}$ & $6,51 \mathrm{aAB}$ & $5,23 \mathrm{~b} \mathrm{AB}$ & 3,06 b C & $2,48 \mathrm{bC}$ & 2,27 b C \\
\hline & AIA & $0,71 \mathrm{aE}$ & $4,05 \mathrm{~b} \mathrm{D}$ & $5,59 \mathrm{bCD}$ & 7,30 a BC & $8,06 \mathrm{aAB}$ & 9,60 a A & $9,12 \mathrm{a} A B$ & 7,23 a BC \\
\hline \multirow{3}{*}{$\begin{array}{l}\text { ESCURO - } \\
\text { AUXINA }\end{array}$} & ANA & $0,61 \mathrm{aE}$ & $5,39 \mathrm{ab} A \mathrm{~B}$ & $6,14 \mathrm{ab} A$ & $5,20 \mathrm{~b} \mathrm{AB}$ & $4,87 \mathrm{~b}$ ABC & $4,24 \mathrm{cBC}$ & $3,42 \mathrm{cCD}$ & $2,50 \mathrm{bD}$ \\
\hline & AlB & $0,55 \mathrm{a} \mathrm{C}$ & 6,83 a $A B$ & 7,82 a A & 8,03 a A & $5,01 \mathrm{~b} \mathrm{~B}$ & $6,84 \mathrm{bAB}$ & $6,10 \mathrm{bAB}$ & 6,23 a $A B$ \\
\hline & AIA & $1,35 \mathrm{aE}$ & $2,94 \mathrm{~b} \mathrm{D}$ & $8,08 \mathrm{aC}$ & 8,24 a BC & 9,36 a ABC & 11,59 a A & $10,49 a \mathrm{AB}$ & 10,18 a ABC \\
\hline \multirow{2}{*}{$\begin{array}{l}\text { LUZ- } \\
\text { AUXINA }\end{array}$} & ANA & $1,33 \mathrm{aE}$ & 6,48 a $\mathrm{A}$ & $5,69 \mathrm{~b} A B$ & $4,22 \mathrm{~b} \mathrm{BC}$ & $3,18 \mathrm{CCD}$ & $2,71 \mathrm{cD}$ & $1,98 \mathrm{CD}$ & $1,92 \mathrm{bDE}$ \\
\hline & AIB & $1,35 \mathrm{a} \mathrm{E}$ & $5,10 \mathrm{a} D$ & $5,23 \mathrm{bCD}$ & 6,64 a BCD & $7,02 \mathrm{~b} \mathrm{BC}$ & 7,75 b B & $7,81 \mathrm{~b} \mathrm{~B}$ & $10,07 \mathrm{aA}$ \\
\hline
\end{tabular}

${ }^{1}$ Médias seguidas por mesma letra minúscula na coluna não diferem entre si para o fator fonte de auxinas, dentro dos fatores tipo de cultivo e concentração, e médias seguidas por mesma letra maiúscula na linha não diferem entre si para o fator concentração, dentro dos fatores fonte de auxina e tipo de cultivo (Coeficiente de variação: 11,08$)$. 
Quanto ao comprimento das raízes obtido nas brotações, as respostas foram similares às observadas para o número das mesmas, sendo o AIA mais efetivo em altas concentrações e o AIB e o ANA em baixas, em todos os sistemas de cultivo testados (Tabela 4). Este resultado está condizente com o efeito das auxinas na indução e crescimento de raízes adventícias. A presença de auxina é necessária na fase de indução do sistema radicular, conforme se aumenta a concentração da auxina, diminui o comprimento das raízes nos meios com AIB e ANA, podendo ocasionar a inibição completa do crescimento da raiz (Salisbury \& Roos, 1991). Quanto ao sistema de cultivo, brotações cultivadas no escuro-auxina e luz-auxina apresentaram maior comprimento radicular ou não diferiram significativamente dos cultivos com auxina constante no meio, para todas as auxinas, na maioria das concentrações testadas (Tabela 4). Estes resultados concordam com Grattapaglia \& Machado (1990), que citam que altas concentrações de auxina, durante o enraizamento, podem manifestar-se na fase de alongamento das raízes, impedindo o crescimento das mesmas. Assim, a remoção da auxina do meio reverteu estes efeitos prejudiciais. Estes resultados estão de acordo com De Klerk et al. (1997), que, trabalhando com cvs. de macieira, obtiveram alongamento das raízes, pelo uso da técnica da dupla fase.

TABELA 4 - Comprimento de raiz por explante enraizado do porta-enxerto M-9-FAEM/UFPel, 2001

\begin{tabular}{|c|c|c|c|c|c|c|c|c|c|}
\hline \multirow{2}{*}{$\begin{array}{l}\text { TIPOS DE } \\
\text { CULTIVO } \\
\end{array}$} & \multirow[b]{2}{*}{ AUXINAS } & \multicolumn{8}{|c|}{ CONCENTRAÇÕES ( M) } \\
\hline & & 0,0 & 0,5 & 1,0 & 5,0 & 10 & 20 & 50 & 100 \\
\hline & AIA & $1,37 a^{1} \mathrm{C}$ & $3,78 \mathrm{bB}$ & 4,13 b B & 5,20 a A & $4,65 \mathrm{aAB}$ & $3,93 \mathrm{aB}$ & $3,83 \mathrm{aB}$ & $3,74 \mathrm{aB}$ \\
\hline \multirow{3}{*}{$\begin{array}{c}\text { ESCURO + } \\
\text { AUXINA }\end{array}$} & ANA & $1,30 \mathrm{aC}$ & $4,93 \mathrm{aA}$ & 5,21 a $A$ & $2,70 \mathrm{bB}$ & $1,85 \mathrm{~b} B \mathrm{C}$ & $1,17 \mathrm{bC}$ & $0,00 \mathrm{bD}$ & $0,00 \mathrm{bD}$ \\
\hline & AlB & $1,32 \mathrm{aC}$ & $5,05 a \mathrm{~A}$ & $4,76 \mathrm{ab} \mathrm{A}$ & 2,96 b B & $1,77 \mathrm{bC}$ & 1,02 b CD & $0,00 \mathrm{bD}$ & $0,00 \mathrm{bD}$ \\
\hline & AIA & 2,87 a B & $4,62 \mathrm{aA}$ & 4,70 a A & $3,66 a A B$ & $3,61 a A B$ & $4,37 \mathrm{aA}$ & $4,17 \mathrm{aA}$ & $3,79 \mathrm{aAB}$ \\
\hline \multirow{3}{*}{$\begin{array}{c}\text { LUZ + } \\
\text { AUXINA }\end{array}$} & ANA & $2,35 \mathrm{aB}$ & 3,96 a A & 3,90 a A & $1,30 \mathrm{bC}$ & $1,23 \mathrm{bC}$ & $1,00 \mathrm{bC}$ & $0,90 \mathrm{bC}$ & $0,78 \mathrm{bC}$ \\
\hline & AlB & $2,87 \mathrm{aB}$ & $04,83 a \mathrm{~A}$ & 4,70 a A & $1,76 \mathrm{bC}$ & $1,38 \mathrm{bCD}$ & 0,85 b CDE & $0,47 \mathrm{~b} D E$ & $0,25 \mathrm{bE}$ \\
\hline & AIA & $1,37 \mathrm{aC}$ & $4,38 \mathrm{ab} \mathrm{B}$ & $5,53 \mathrm{aA}$ & 5,43 a A & $5,93 \mathrm{aA}$ & $6,40 \mathrm{aA}$ & 6,08 a A & $5,60 \mathrm{aA}$ \\
\hline \multirow{3}{*}{$\begin{array}{l}\text { ESCURO - } \\
\text { AUXINA }\end{array}$} & ANA & 1,26 a CDE & $5,12 \mathrm{aA}$ & 5,46 a A & $2,71 b B$ & $2,28 \mathrm{cBC}$ & $1,93 \mathrm{~b} \mathrm{BCD}$ & $1,00 \subset \mathrm{CDE}$ & $0,67 c E$ \\
\hline & $A \mid B$ & $1,37 \mathrm{aE}$ & $3,44 \mathrm{bBC}$ & $3,41 \mathrm{bBC}$ & 4,76 a A & $3,75 b$ B & $2,67 \mathrm{~b} C D$ & $2,56 \mathrm{~b} \mathrm{CD}$ & $2,12 \mathrm{~b} D E$ \\
\hline & ÄIÄ & $2,26 \mathrm{aC}$ & $3,94 \mathrm{bB}$ & $3,80 \mathrm{~b} \mathrm{~B}$ & $3,96 \mathrm{a} B$ & $4,20 \mathrm{aB}$ & $4,40 \mathrm{aB}$ & $4,56 \mathrm{aB}$ & $5,51 \mathrm{aA}$ \\
\hline \multirow{2}{*}{$\begin{array}{l}\text { LUZ. } \\
\text { AUXINA }\end{array}$} & ANA & $2,20 \mathrm{aC}$ & 5,93 a A & $6,05 a A$ & $3,84 \mathrm{aB}$ & $1,98 \mathrm{bCD}$ & 1,55 c CDE & $1,07 \mathrm{cDE}$ & $0,78 \mathrm{bE}$ \\
\hline & AlB & $2,25 \mathrm{aC}$ & $4,63 \mathrm{bA}$ & $4,74 \mathrm{bA}$ & 3,96 a $A B$ & $3,56 \mathrm{a} B$ & $3,23 \mathrm{bB}$ & $1,98 \mathrm{bC}$ & $1,71 \mathrm{bC}$ \\
\hline
\end{tabular}

${ }^{1}$ Médias seguidas por mesma letra minúscula na coluna não diferem entre si para o fator fonte de auxinas, dentro dos fatores tipo de cultivo e concentração, e médias seguidas por mesma letra maiúscula na linha não diferem entre si para o fator concentração, dentro dos fatores fonte de auxina e tipo de cultivo (Coeficiente de variação: 22,53).

Brotações tratadas com AIA apresentaram bom sistema radicular, ou seja, não houve formação de raízes grossas, ocorreu maior presença de raízes secundárias, menor formação de calo e um bom desenvolvimento da parte aérea, sendo que a formação de calo ocorreu apenas nas concentrações mais altas (Figura 1). Em contrapartida, brotações enraizadas com AIB e ANA apresentaram raízes menos espessas e sem formação de calo apenas nas concentrações mais baixas, ou seja, 0,5 e 1,0 $\mu \mathrm{M}$, ocorrendo formação de raízes mais grossas e de calo com o aumento da concentração (Figura 2). Esta diferença entre as auxinas pode ser devida à maior degradação e menor taxa de absorção de AIA em relação às outras auxinas, que determinaria acúmulo de ANA e AIB nas células dos explantes (Nissen \& Sutter, 1990).

$\mathrm{Na}$ fase de aclimatização, plantas tratadas com AIB e ANA obtiveram alta porcentagem de aclimatização apenas nas concentrações de 0,5 e 1,0 $\mu \mathrm{M}$, enquanto nos tratamentos com AIA, esta porcentagem manteve até $20 \mu \mathrm{M}$ (Tabela 5). A baixa porcentagem de sobrevivência das plantas tratadas com AIB e ANA na concentração de 5,0 $\mu \mathrm{M}$ e a não-sobrevivência destas, nos tratamentos com as concentrações superiores, ocorreram em função do tipo de raiz e da parte aérea formada, ou seja, ocorreu a formação de raízes mais espessas e formação de calo na base do explante original, como também baixo desenvolvimento da parte aérea. Estas respostas estão de acordo com Mohammed \& Vidaver (1990), que relatam que não é somente o tipo de sistema radicular que determina a sobrevivência após a transferência do in vitro para as condições ex vitro, ou seja, o bom desenvolvimento da parte aérea também é fundamental. Altas concentrações de auxinas, além de induzirem maior formação de calo, que pode ser uma barreira para a passagem de nutrientes e água para a parte superior da planta, também ocasiona baixo desenvolvimento da parte aérea em função do excesso de auxina, o qual causa toxidez à planta, levando a uma senescência foliar, comprometendo sua sobrevivência (Grattapaglia \& Machado, 1998). O contrário ocorreu com as plantas tratadas nas concentrações de 0,5 e $1,0 \mu \mathrm{M}$, as quais apresentaram um bom sistema radicular, bom desenvolvimento da parte aérea e pouco ou sem formação de calo, obtendo, assim, alta porcentagem de sobrevivência. Estas características também foram verificadas nos tratamentos com AIA, porém em uma faixa mais ampla de concentrações, ou seja, de 0,5 a $20 \mu \mathrm{M}$, como também das plantas obtidas do tratamento- controle. Isto significa que raízes mais finas, ramificadas e sem a presença de calo determinam melhores condições para uma boa aclimatização.

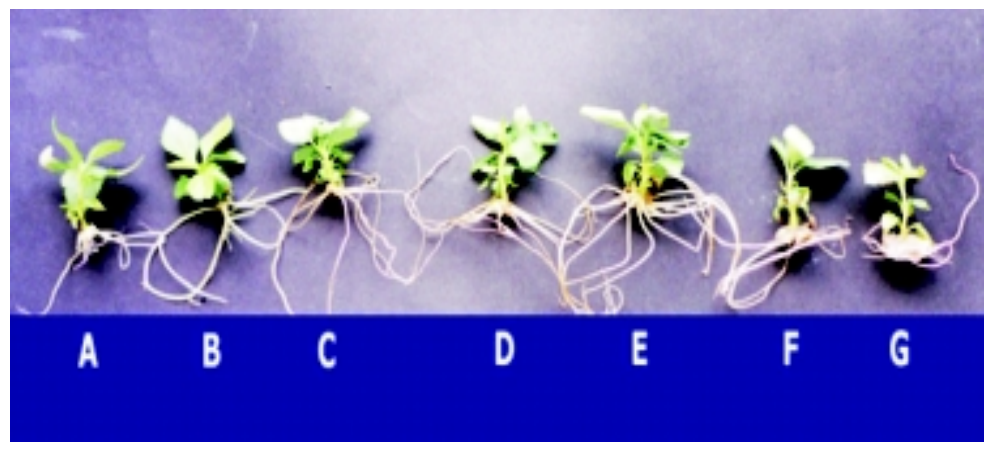

FIGURA 1- Plantas de macieira cultivar M-9 oriundas das diferentes concentrações de AIA - A) 0,5; B) 1,0; C) 5,0; D) 10; E) 20; F) 50 ; G) $100 \mu \mathrm{M}$, obtidas durante o enraizamento in vitro no cultivo escuro+auxina.

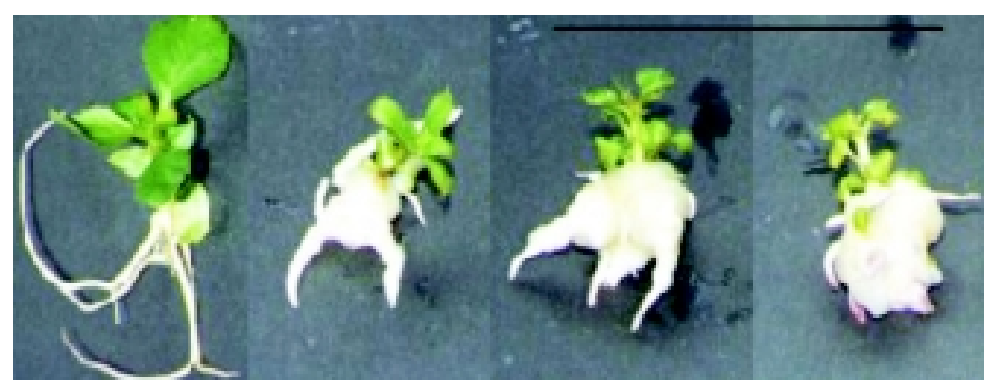

FIGURA 2- Plantas de macieira cultivar M-9 oriundas das diferentes concentrações de ANA - A) 0,5; B) 5,0; C) 20; D) $50 \mu \mathrm{M}$, obtidas durante o enraizamento in vitro no cultivo luz+auxina.

TABELA 5- Porcentagem de sobrevivência de plantas do porta-enxerto M-9 - FAEM/UFPel, 2001 CONCENTRAÇ̃ES ( M)

\begin{tabular}{ccccccccc} 
AUXINAS & 0,0 & 0,5 & 1,0 & 5,0 & 10 & 20 & 50 & 100 \\
\hline AlA & $75,59 \mathrm{a}^{\prime} \mathrm{A}$ & $78,66 \mathrm{aA}$ & $84,51 \mathrm{aA}$ & $86,88 \mathrm{aA}$ & $87,06 \mathrm{aA}$ & $84,32 \mathrm{aA}$ & $31,76 \mathrm{ab}$ & $28,41 \mathrm{a} \mathrm{B}$ \\
ANA & $73,26 \mathrm{aA}$ & $88,42 \mathrm{aA}$ & $88,42 \mathrm{aA}$ & $2,29 \mathrm{bB}$ & $0,00 \mathrm{bB}$ & $0,00 \mathrm{bB}$ & $0,00 \mathrm{bB}$ & $0,00 \mathrm{bB}$ \\
AlB & $72,95 \mathrm{aA}$ & $87,30 \mathrm{aA}$ & $84,77 \mathrm{aA}$ & $1,37 \mathrm{bB}$ & $0,00 \mathrm{bB}$ & $0,00 \mathrm{bB}$ & $0,00 \mathrm{bB}$ & $0,00 \mathrm{bB}$
\end{tabular}

${ }^{1}$ Médias seguidas de mesma letra minúscula na coluna não diferem entre si para o fator fonte de auxina, dentro do fator concentração, e médias seguidas por mesma letra maiúscula na linha não diferem entre si para o fator concentração, dentro do fator auxina. 


\section{CONCLUSÕES}

1. As auxinas aumentam o enraizamento in vitro do porta-enxerto de macieira M-9.

2. O AIA induz melhor enraizamento em concentrações mais altas, e o AIB e o ANA em concentrações intermediárias.

3. Os sistemas de cultivo escuro-auxina e luz-auxina proporcionam melhor enraizamento.

4. O AIA proporciona maior porcentagem de sobrevivência numa ampla escala de concentrações, e o ANA e o AIB nas concentrações mais baixas.

\section{REFERÊNCIASBIBLIOGRÁFICAS}

ABPM. Produção, exportação, importação, empregos gerados. Disponível em: http.www.abpm.org. acesso em: 30 de maio de 2002.

ASSIS, T.F. de; TEIXEIRA, S.L. Enraizamento de plantas lenhosas. In: TORRES, A.C.; CALDAS, L.S., BUSO, J.A. Cultura de tecidos e transformação genética de plantas. Brasília: Embrapa-SPI/EmbrapaCNPH, 1998. p. 261-296.

BARRIT, B.H. Apple orchad mANAgement. In: ENFRUTE, 2, 1999, Anais... FrAIBurgo, SC, 1999. p.1-7.

BORGES, A.L.; ALVES, E.J.; SILVA, de; SOUZA, L.da S.; MATOS, A.P. de; FANCELLI, M.; OLIVEIRA, A.M.G.; CORDEIRO, Z.J.M.; SILVEIRA, J.R.S.; COSTA, D. da C.; MEDINA, V.M.; OLIVEIRA, S.L.; SOUZA, J.S. de; OLIVEIRA, R.P; CARDOSO, C.E.L.; MATSUURA, F.C.A.U.; ALMEIDA, C.O. de. O cultivo da banana. Cruz das Almas: EMBRAPA-CNPMF, 1997. 109p. (circular técnica).

CALDAS, L.S.; HARIDISAN, P.; FERREIRA, M.E. Meios nutritivos. In TORRES, A.C.; CALDAS, L.S. Técnicas e aplicações da cultura de tecidos de plantas. Brasília: ABCTP/Embrapa-CNPH,1990. p. 37-70.

CENTELLAS, A.Q.; FORTES, G.R. de L.; MÜLLER, N.T.G.; ZANOL, G.C.; FLORES, R.; GOTTINARI, R.A. Efeito de auxinas sintéticas no enraizamento in vitro de macieira. Pesquisa Agropecuária Brasileira, Brasília, v.34, n.2, p.181-186, 1999.

DE KLERK, G.J.; JOLANDA, T. B.; SVETLA, M. Effectiveness of indoleacetic acid, indolbutyric acid and napthaleneacetic acid, during adventitious root formation in vitro in Malus Jork 9. Plant Cell, Rockville, v.49, 39-44, 1997.

FERRI, V. C.; FORTES, G.R. de L. Avaliação da eficácia de três reguladores de crescimento no enraizamento in vitro de kiwi (Actinidia deliciosa, A. chev) cv. Matua. In: ENCONTRO BRASILEIRO DE BIOTECNOLOGIA VEGETAL, 1, 1993, Brasília. Resumos: p. 126.

FETT NETO,A.G.; TEIXEIRA, S.L.; SILVA, E.A.M.; SANTNNA, R. Biochemical and morphological changes during in vitro rhizogenesis in cuttings of Sequoia sempervirens (D. Don) Endl. Journal of Plant Physiology, Stuttgart, v. 140, p. 720-728, 1992.

GRATTAPAGLIA, D.; MACHADO, M.A. Micropropagação. In: TORRES, C.A.; CALDAS, L.S. Técnicas e aplicações da cultura de tecidos de plantas. Brasília. ABCTP/EMBRAPA-CNPH, 1990, p.99-169.

GRATTAPAGLIA, D.; MACHADO, M. A. Micropropagação. In: TORRES, A.C.; CALDAS, L.S.; BUSO, J.A. Cultura de tecidos e transformação genética de plantas. Brasília: Embrapa-SPI/Embrapa-CNPH, 1998. p.183-260.

LEE, H.J.; KO, K.C. Effects of culture media and plant hormones os shoot tip culture of Fuji apple cultivar (Malus domestica Borkh). Agricultural Research, Washington, v.9, n.1, 67-77, 1984.

LEITE, D.L.; PETERS, J.A.; FORTES, G.R.de L.; NAKASU, B.H. Micropropagação de pereira (Pyrus spp.) cultivar Carrick. Revista Brasileira de Fruticultura, Jaboticabal-SP, v.16, n.1, 236-241, 1994.

MAGALHÃES Jr. A.M.; PETERS, J.A., Cultura in vitro de ameixeira: Efeito do ácido indolbutírico, tipo de lâmpada e intensidade luminosa no enraizamento. Revista Brasileira de Fisiologia Vegetal, Londrina/PR, v.3, n.1, p.57-61, 1991.

MAENE, L.; DEBERGH, P.C. Optimalization of the transfer of tissue cultures shoots to in vitro condition. Acta Horticulture, Wageningen, V.12,p. 335-342, 1987

MOHAMMED, G.H.; VIDAVER, W.E. The influence of aclimatization treatment and planted morphology $\mathrm{n}$ early greenhouse performance of tissue-cultured. Plant Cell Tissue, Holanda, v.21, 111-117, 1990.

MURASHIGE, T.; SKOOG, F. A revised medium for rapid growth and biossays with tobacco tissue cultures. Physiologia Plantarum, v.15, p.473-479, 1962.

NISSEN, J.S; SUTTER, E.G. Stability of AIA and AIB in nutrient medium of several tissue culture procedures. HortScience, Alexandria/VA, v. $25,800-802,1990$.

NUNES, J.C.; de O.; BARPP, A.; SILVA, F.C.; PEDROTI, E.L. Micropropagação do porta-enxerto Marubakaido (Malus prunifolia), a partir da cultura de meristema. Revista Brasileira de Fruticultura, Cruz das Almas, v.21, n.2, p.191-195, 1999.

PAQUAL, M.; PEIXOTO, P.H.P; SANTOS, J.C. dos; PINTO, J.E.B.P. Propagação in vitro da amoreira-preta (Rubus sp) cv. Ébano: Uso de reguladores de crescimento. Ciência e Prática, Lavras, v.15, n.3, p.282-286, 1991

SALISBURY, F. B.; ROOS, C.W. Plant Physiology. Wadswoth, California: 1991. cap.17, p.357-378.

SMULDERS, M.J.M; VAN DE VEM, E.T.W.M.; CROES, A.F.; WULLEMS, G.J. Metabolism of 1-naphthaleneacetic acid and explants of tabacco evidence for release of free hormone from conjugates. Jounal Plant Growth Regulation, v.9, 27-34, 1990.

TAIZ, L.; ZEIGER, E. Plant physiology, Redwood City California: 1991. cap.16, p.398-424.

VAN DER KRIEKEN, W.M.; BRETELER, H.; VISSER, M.H.M.; MAVRIDOU, D. The role of conversion of AIB into AIA on root regeneration in apple: introduction of a test system. Plant Cell Reports, Berlin, v.12, 203-206, 1993.

VESCO, L.L.D.; GUERRA, M.P.; Organogênese e micropropagação da goiabeira serrana (Feijoa sellowiana) Berg. Revista Brasileira de Fruticultura, Jaboticabal/SP, v.21, n.1, p. 60-64, 1999.

ZANOL, G.C. Enraizamento in vitro do porta-enxerto Marubakaido (Malus domestica) afetado pela exposição de períodos de escuro, concentrações de ácido indolbutírico e floroglucinol. Dissertação (Mestrado em Agronomia - Fruticultura de Clima Temperado) Faculdade de Agronomia Eliseu Maciel. Universidade Federal de Pelotas, Pelotas, 1996, 81f.

ZANOL,G.C.; FORTES,G.R.de L.; BAPTISTA DA SILVA,J.; FARIA,J.T.C.; GOTTINARI, R.A.; CENTELLAS,A.Q. Uso do Ácido indolbutírico e do escuro no enraizamento in vitro do porta-enxerto de macieira Marubakaido. Ciência Rural, Santa Maria/RS, v.28, n.3, p.387-391. 1998 . 